\title{
Uncertainty in Twenty-First-Century CMIP5 Sea Level Projections
}

\author{
CHRISTOPHER M. LITTLE* \\ Woodrow Wilson School of Public and International Affairs, Princeton University, Princeton, New Jersey \\ RADLEY M. HORTON \\ Center for Climate Systems Research, Columbia University, New York, New York \\ ROBERT E. KOPP \\ Department of Earth and Planetary Sciences, Rutgers Energy Institute, and Institute of Earth, Ocean and \\ Atmospheric Sciences, Rutgers, The State University of New Jersey, New Brunswick, New Jersey \\ MiCHAEL OPPENHEIMER \\ Woodrow Wilson School of Public and International Affairs, and Department of Geosciences, Princeton \\ University, Princeton, New Jersey \\ STAN YIP \\ Department of Applied Mathematics, Hong Kong Polytechnic University, Hong Kong, China
}

(Manuscript received 25 June 2014, in final form 10 September 2014)

\begin{abstract}
The representative concentration pathway (RCP) simulations included in phase 5 of the Coupled Model Intercomparison Project (CMIP5) quantify the response of the climate system to different natural and anthropogenic forcing scenarios. These simulations differ because of 1) forcing, 2) the representation of the climate system in atmosphere-ocean general circulation models (AOGCMs), and 3) the presence of unforced (internal) variability. Global and local sea level rise projections derived from these simulations, and the emergence of distinct responses to the four RCPs depend on the relative magnitude of these sources of uncertainty at different lead times. Here, the uncertainty in CMIP5 projections of sea level is partitioned at global and local scales, using a 164-member ensemble of twenty-first-century simulations. Local projections at New York City (NYSL) are highlighted. The partition between model uncertainty, scenario uncertainty, and internal variability in global mean sea level (GMSL) is qualitatively consistent with that of surface air temperature, with model uncertainty dominant for most of the twenty-first century. Locally, model uncertainty is dominant through 2100, with maxima in the North Atlantic and the Arctic Ocean. The model spread is driven largely by 4 of the 16 AOGCMs in the ensemble; these models exhibit outlying behavior in all RCPs and in both GMSL and NYSL. The magnitude of internal variability varies widely by location and across models, leading to differences of several decades in the local emergence of RCPs. The AOGCM spread, and its sensitivity to model exclusion and/or weighting, has important implications for sea level assessments, especially if a local risk management approach is utilized.
\end{abstract}

\footnotetext{
* Current affiliation: Atmospheric and Environmental Research, Inc., Lexington, Massachusetts.
}

Corresponding author address: Christopher Little, Atmospheric and Environmental Research, Inc., 131 Hartwell Ave., Lexington, MA 02421.

E-mail: clittle@aer.com

\section{Introduction}

Coastal flood risk assessments require the characterization of the magnitude and sources of uncertainty in future local sea level (LSL; NPCC2 2013; Hinkel et al. 2014; Kopp et al. 2014). LSL is influenced by atmospheric, oceanic, glaciological, and geological processes (Stammer et al. 2013; Milne et al. 2009), and the local

DOI: 10.1175/JCLI-D-14-00453.1 
signature and time evolution of these processes is expected to vary in the future (Church et al. 2011, 2014; Kopp et al. 2014). However, changes in the ocean's thermodynamic properties, mass distribution, and dynamics, driven by the coupled ocean-atmosphere system, underlie much of the observed variability in LSL (Stammer et al. 2013). These processes, here collectively referred to as the "oceanographic component" of sea level change, are expected to continue to play a large role in driving twenty-first-century sea level trends, especially along the northeastern U.S. coastline (Yin and Goddard 2013; Kopp et al. 2014).

Atmosphere-ocean general circulation models (AOGCMs) included in Phase 5 of the Coupled Model Intercomparison Project (CMIP5; Taylor et al. 2012) project the coupled ocean-atmosphere response to twenty-first-century anthropogenic and natural forcings [representative concentration pathways (RCPs); also referred to here as scenarios]. These simulations constitute an ensemble of opportunity and thus may not span the full range of possible future climates (Tebaldi and Knutti 2007; Reichler and Kim 2008; Knutti et al. 2010). However, uncertainty associated with RCPs, model formulation, and internal variability can be quantified and compared (Sansom et al. 2013; Yip et al. 2011; Hawkins and Sutton 2009). These studies provide insight into AOGCM-derived sea level projections at different lead times and spatial scales, informing assessments and uncertainty reduction efforts.

CMIP5 simulations have been analyzed as an ensemble to assess the oceanographic component of future sea level changes (e.g., Kopp et al. 2014; Slangen et al. 2014; Pardaens et al. 2011; Yin 2012; Perrette et al. 2013). Generally, these multimodel ensemble projections include some measure of uncertainty. For example, the recent Intergovernmental Panel on Climate Change Fifth Assessment Report (AR5; Church et al. 2014) presents a likely (67\%) range of projections conditional on RCP, but the assessment does not indicate the relative contribution of model and scenario uncertainty at a local level. In other assessments, a reduced subset of the available models, realizations, and forcing scenarios has been used (NPCC2 2013; National Research Council 2012). The influence of these largely subjective and/or practical choices is unclear. Furthermore, there has been limited attention on the role of internal variability on LSL at different projection lead times. Using a 40-member ensemble of Community Climate System Model (CCSM) simulations, $\mathrm{Hu}$ and Deser (2013) highlight the importance of internal variability. However, their analysis uses only one model and a single forcing scenario, and it does not extend beyond 2060 .
Here, we use the analysis of variance (ANOVA) decomposition of Yip et al. (2011) to partition sources of uncertainty in the decadally averaged oceanographic component of sea level change arising from different RCPs, AOGCMs, and internal variability across the CMIP5 ensemble. We present these sources of uncertainty at two lead times. The first, 2040, corresponds to a roughly 25 -yr adaptation planning horizon; the second, 2090 , is relevant to long-term ( $\sim 75$ years) planning efforts and is comparable to projections examined in other analyses. We examine ensemble and model-by-model projections in the global mean and in New York City (NYC). Using a new metric, we show when RCP-driven sea level trends emerge (i.e., when projections become scenario dependent) and how this "crossover time" varies by location and AOGCM. We highlight the implications of model spread and outliers on future assessments.

\section{Methods}

We analyze changes in decadal mean sea level in CMIP5 "historical" and "RCP" simulations archived at the Program for Climate Model Diagnosis and Intercomparison (PCMDI; http://cmip-pcmdi.llnl.gov/cmip5/), using the subset (16) of AOGCMs that include simulations for the complete range of RCP scenarios (RCP2.6, RCP4.5, RCP6.0, and RCP8.5). Many of these models utilize multiple realizations run from different initial conditions. The list of models and number of realizations in the ensemble are shown in Table 1.

CMIP5 output fields are split into a global mean sea level $(h)$ and a local anomaly $(\eta)$. We perform the same corrections to these fields as Yin (2012), including removing the linear drift from global mean sea level change in the preindustrial control runs (Gupta et al 2013). The decadal mean, local sea level rise (SLR, where positive is an increase from the 1986-2005 baseline) for a CMIP5 simulation is given by

$$
\operatorname{SLR}_{m, r, s}(t, x, y)=\Delta h_{m, r, s}(t)+\Delta \eta_{m, r, s}(t, x, y),
$$

where $\Delta$ is the change at time $t$ from the 1986 to 2005 mean and $s, m$, and $r$ indicate the RCP scenario, ocean model, and realization, respectively.

CMIP5 ocean models use a variety of curvilinear grids, which we interpolate to a common $0.5^{\circ} \times 0.5^{\circ}$ grid. Grid points are included in the multimodel analysis only if they include data from all models. The SLR at NYC is taken from the grid point nearest the Battery tide gauge $\left(40.25^{\circ} \mathrm{N}, 74.25^{\circ} \mathrm{W}\right)$.

To partition sources of uncertainty, we adopt the ANOVA decomposition of Yip et al. (2011). For each 
TABLE 1. List of model simulations included in the ensemble.

\begin{tabular}{|c|c|c|c|c|c|c|c|}
\hline \multirow[b]{2}{*}{ Modeling center } & \multirow[b]{2}{*}{ Model name } & \multirow[b]{2}{*}{ Model expansion } & \multicolumn{4}{|c|}{$\mathrm{RCP}$} & \multirow[b]{2}{*}{ Total } \\
\hline & & & 2.6 & 4.5 & 6.0 & 8.5 & \\
\hline $\begin{array}{l}\text { Beijing Climate Center (BCC), } \\
\text { China Meteorological Administration }\end{array}$ & BCC_CSM1.1 & $\begin{array}{l}\text { BCC, Climate System } \\
\text { Model, version } 1.1\end{array}$ & 1 & 1 & 1 & 1 & 4 \\
\hline BCC, China Meteorological Administration & BCC_CSM1.1M & $\begin{array}{l}\text { BCC_CSM1.1 } \\
\text { (moderate resolution) }\end{array}$ & 1 & 1 & 1 & 1 & 4 \\
\hline National Center for Atmospheric Research & CCSM4 & $\begin{array}{l}\text { Community Climate } \\
\text { System Model, version } 4\end{array}$ & 4 & 4 & 4 & 4 & 16 \\
\hline $\begin{array}{l}\text { Commonwealth Scientific and Industrial } \\
\text { Research Organisation (CSIRO) in } \\
\text { collaboration with Queensland Climate } \\
\text { Change Centre of Excellence }\end{array}$ & CSIRO Mk3.6.0 & CSIRO Mark 3.6.0 & 10 & 10 & 10 & 10 & 40 \\
\hline $\begin{array}{l}\text { National Oceanic and Atmospheric } \\
\text { Administration (NOAA) Geophysical } \\
\text { Fluid Dynamics Laboratory (GFDL) }\end{array}$ & GFDL CM3 & GFDL Climate Model, version 3 & 1 & 1 & 1 & 1 & 4 \\
\hline NOAA GFDL & GFDL-ESM2M & $\begin{array}{l}\text { GFDL Earth System Model } \\
\text { with MOM, version } 4 \\
\text { component }\end{array}$ & 1 & 1 & 1 & 1 & 4 \\
\hline NOAA GFDL & GFDL-ESM2G & $\begin{array}{l}\text { GFDL Earth System Model } \\
\text { with GOLD component }\end{array}$ & 1 & 3 & 1 & 1 & 6 \\
\hline $\begin{array}{l}\text { National Aeronautics and Space } \\
\text { Administration (NASA) Goddard } \\
\text { Institute for Space Studies (GISS) }\end{array}$ & GISS-E2-R & $\begin{array}{l}\text { GISS Model E2, coupled } \\
\text { with the Russell ocean model }\end{array}$ & 3 & 16 & 3 & 3 & 25 \\
\hline Met Office Hadley Centre & HadGEM2-ES & $\begin{array}{l}\text { Hadley Centre Global } \\
\text { Environment Model, version } \\
\text { 2-Earth System }\end{array}$ & 4 & 4 & 4 & 4 & 16 \\
\hline L'Institut Pierre-Simon Laplace (IPSL) & IPSL-CM5A-LR & $\begin{array}{l}\text { IPSL Coupled Model, version 5A, } \\
\text { low resolution }\end{array}$ & 4 & 4 & 1 & 4 & 13 \\
\hline $\begin{array}{l}\text { Atmosphere and Ocean Research Institute } \\
\text { (AORI; University of Tokyo), and National } \\
\text { Institute for Environmental Studies (NIES), } \\
\text { and Japan Agency for Marine-Earth Science } \\
\text { and Technology (JAMSTEC) }\end{array}$ & MIROC5 & $\begin{array}{l}\text { Model for Interdisciplinary } \\
\text { Research on Climate, version } 5\end{array}$ & 3 & 3 & 3 & 3 & 12 \\
\hline $\begin{array}{l}\text { JAMSTEC, AORI (University of Tokyo), } \\
\text { and NIES }\end{array}$ & MIROC-ESM & MIROC, Earth System Model & 1 & 1 & 1 & 1 & 4 \\
\hline $\begin{array}{l}\text { JAMSTEC, AORI (University of Tokyo), } \\
\text { and NIES }\end{array}$ & MIROC-ESM-CHEM & MIROC-ESM, Chemistry Coupled & 1 & 1 & 1 & 1 & 4 \\
\hline Meteorological Research Institute (MRI) & MRI-CGCM3 & $\begin{array}{l}\text { MRI Coupled Atmosphere-Ocean } \\
\text { General Circulation Model, } \\
\text { version } 3\end{array}$ & 1 & 1 & 1 & 1 & 4 \\
\hline Norwegian Climate Centre & NorESM1-M & $\begin{array}{l}\text { Norwegian Earth System Model, } \\
\text { version } 1 \text { (intermediate } \\
\text { resolution) }\end{array}$ & 1 & 1 & 1 & 1 & 4 \\
\hline \multirow[t]{2}{*}{ Norwegian Climate Centre } & NorESM1-ME & $\begin{array}{l}\text { NorESM1-M with carbon cycling } \\
\text { (and biogeochemistry) }\end{array}$ & 1 & 1 & 1 & 1 & 4 \\
\hline & Total & & 38 & 53 & 35 & 38 & 164 \\
\hline
\end{tabular}

set of realizations, the model scenario mean is given by $\operatorname{SLR}(m, \cdot, s, t)$; the multimodel mean for each scenario is given by $\operatorname{SLR}(\cdot, \cdot, s, t)$; and the overall mean across all scenarios and models is given by $\operatorname{SLR}(\cdot, \cdot, \cdot, t)$, where the dot indicates an unweighted arithmetic mean. The total sample variance $(T)$ is the sum of four components: that driven by the forcing (RCP) scenario $(S)$, different AOGCMs $(M)$, internal variability $(V)$, and a modelscenario interaction term $(I)$ that accounts for different responses to individual RCPs (see Yip et al. 2011, their Figs. 2 and 6), shown as
$T(x, y, t)=S(x, y, t)+M(x, y, t)+V(x, y, t)+I(x, y, t)$.

All terms of Eq. (2) are calculated as in Yip et al. (2011), except for $V$; we do not include AOGCMs with only one realization in the calculation of this term.

The crossover time $t_{c}$ is defined to occur when the variance driven by scenario and internal variability are equal:

$$
S\left(x, y, t_{c}\right)=V\left(x, y, t_{c}\right) .
$$



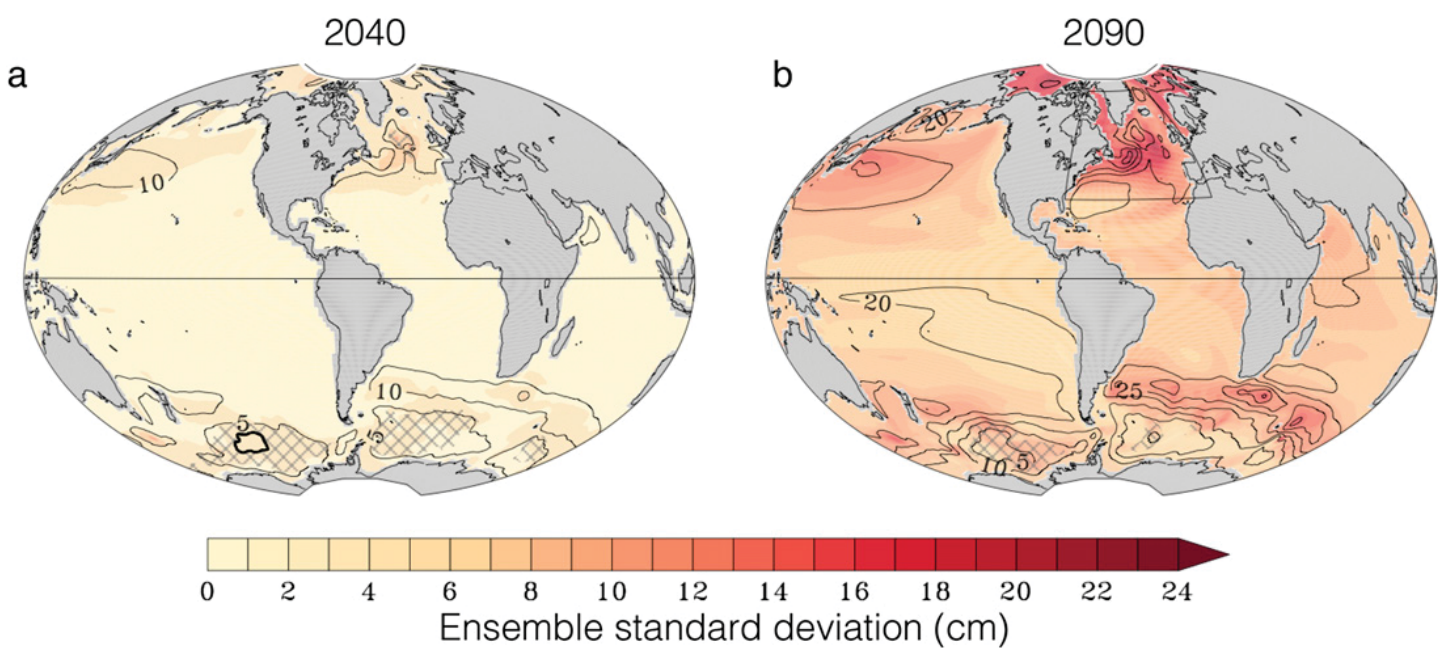

FIG. 1. The (left) 2040 and (right) 2090 multimodel, multiscenario, multirealization decadal mean SLR [SLR( $(\cdot, \cdot, \cdot, t)$, contours, in $\mathrm{cm}$ ] and ensemble standard deviation $\left(T^{0.5}\right.$, shading, in $\left.\mathrm{cm}\right)$. Cross-hatching indicates regions in which the ensemble mean divided by the ensemble standard deviation is less than one $\left(\mu / T^{0.5}<1\right)$. Box indicates the region shown in more detail in Fig. 2.

The crossover time is similar to the "time of emergence" described in Hawkins and Sutton (2012); both metrics quantify when a climate signal is distinguishable from "noise" driven by internal variability. Here, we employ this metric for both the multimodel ensemble and individual models.

\section{Results}

\section{a. Ensemble mean and total uncertainty}

Although the principal focus of this analysis is uncertainty, we produce a multimodel, multiscenario mean projection of the oceanographic component of SLR (contours in Fig. 1). The oceanographic component of global mean sea level (GMSL) exhibits a lagged response to anthropogenic forcing; in this analysis and other studies (e.g., Yin 2012), most sea level rise occurs in the second half of the century, even in RCP simulations in which concentrations stabilize or decrease over this period. Averaged across RCPs, GMSL increases by $8 \mathrm{~cm}$ over the first 40 years of the twenty-first century and by $13 \mathrm{~cm}$ over the subsequent 50 years. The 2090 GMSL rise of $21 \pm 6 \mathrm{~cm}$ from this ensemble compares to $20 \pm 5 \mathrm{~cm}$ from an arithmetic mean of the four RCPs in AR5.

As indicated in Church et al. (2014), the spatial pattern of sea level change is relatively insensitive to RCP. Thus, the multiscenario mean shown in Fig. 1 reflects several robust regional anomalies described by other studies, notably maxima of SLR in the Atlantic and Arctic, particularly later in time (Yin 2012; Bouttes and Gregory 2014; Slangen et al. 2014; Perrette et al. 2013). Although the magnitude of SLR is robust by a simple criterion $\left(\left[\operatorname{SLR}(\cdot, \cdot, \cdot, t) / T^{0.5}\right]>1\right.$, where $T^{0.5}$ is the sample standard deviation) in both time periods in all locations except for the Southern Ocean (where sea level changes are small), its variance can be high at a regional level. Large (absolute) uncertainty is usually associated with regions that exhibit higher SLR, with an exception in the South Pacific, when models indicate a more robust signal.

Figure 2 highlights the oft-discussed twenty-firstcentury sea level rise "hotspot" in the North Atlantic (Yin et al. 2009; Yin and Goddard 2013; Kopp et al. 2014), indicating coherent maxima in both signal and uncertainty. Although NYC is on the southwestern margins of the hotspot, the sea level change averaged over the North Atlantic subpolar gyre and northeastern U.S. coast are highly correlated (Yin et al. 2009), and we use

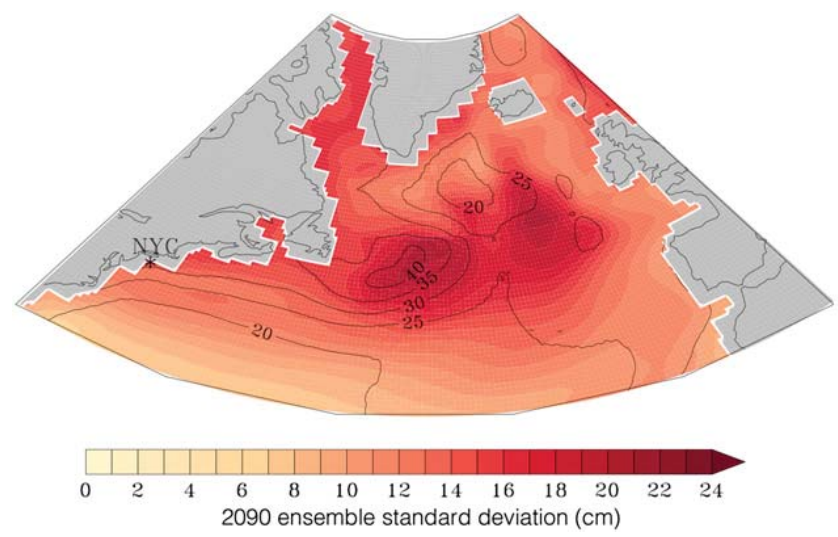

FIG. 2. As in Fig. 1b, but for the North Atlantic (boxed region in Fig. 1b). The asterisk marks the grid point analyzed as NYC in subsequent figures. 
a
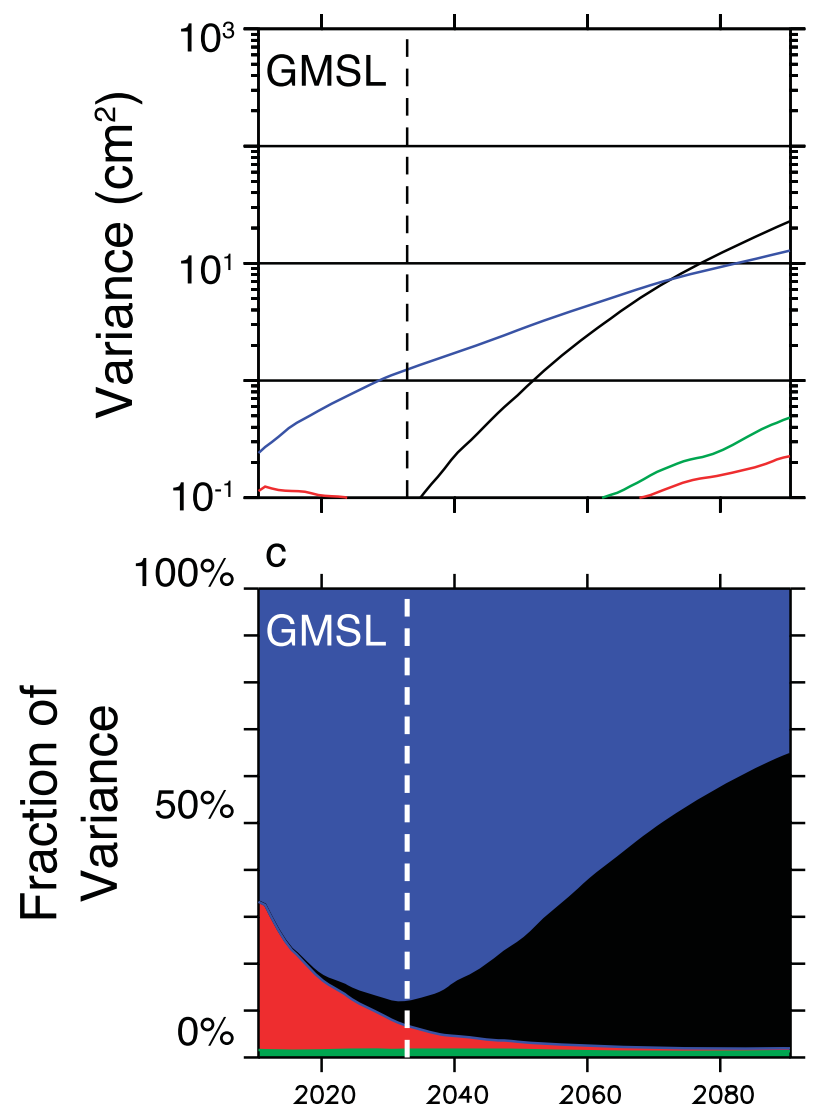

b

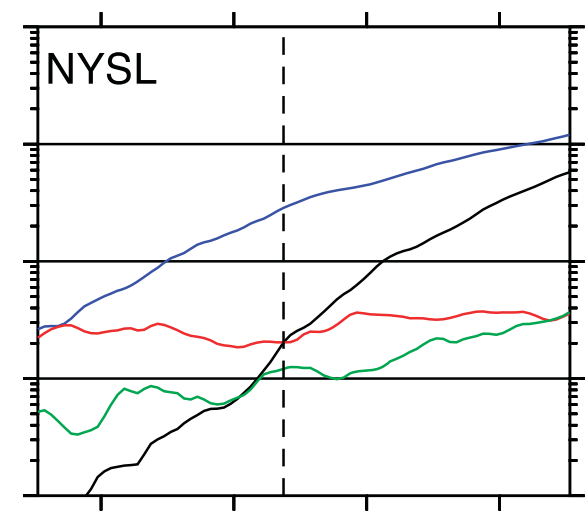

d

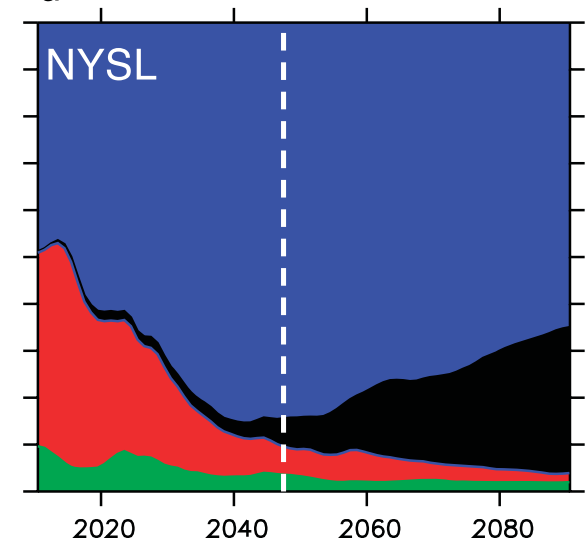

FIG. 3. The uncertainty in decadal mean (a) GMSL and (b) NYSL contributed by each component of the total variance [black, scenario, $S(t)$; blue, model, $M(t)$; red, internal, $V(t)$; green, model scenario, $I(t)$ ]. (c),(d) The fraction of the variance in SLR at each location driven by each component. Dashed vertical line indicates the crossover time.

the sea level at NYC (NYSL) in the remainder of the paper because 1) it is a marker for the hotspot at a coastal location and 2) New York City has significant exposure of coastal assets (Hallegatte et al. 2013; NPCC2 2013).

\section{b. Partitioning uncertainty}

We decompose the sources of uncertainty in these ensemble projections in Fig. 3, which illustrates their temporal evolution, and Fig. 4, which shows global snapshots of the main effects $(S, M$, and $V)$ in 2040 and 2090.

The evolution of uncertainty in GMSL (Figs. 3a,c) is qualitatively consistent with projections of global mean surface air temperature (Yip et al. 2011; Hawkins and Sutton 2009). Model uncertainty is the largest source of uncertainty through most of the twenty-first century, increasing monotonically through the period. However, the rate of increase in scenario uncertainty is higher throughout the twenty-first century, and this quantity increases to $65 \%$ of the variance by 2090 . Uncertainty driven by internal variability is comparable to that of scenario uncertainty before 2035 (the crossover time) but decreases to a negligible component of the total uncertainty by the late twenty-first century.

As expected, uncertainty is higher for all sources at a local level (Figs. 3b,d; Hawkins and Sutton 2009). Although the absolute uncertainty arising from internal variability is relatively constant throughout the century in NYSL, its fractional contribution is initially much higher than in GMSL (up to $\sim 50 \%$, compared to $<30 \%$ globally) and takes longer to decay. Both model and scenario uncertainty are higher in NYSL than in GMSL, but model uncertainty is dominant throughout the twenty-first century, remaining greater than $65 \%$ through 2090. Model-scenario interaction grows over time, indicating that models have a different response to individual RCPs, but this term remains small compared to the main effects.

At almost all locations, sea level change remains scenario independent in 2040 (Fig. 4a). By 2090, the response to RCPs is apparent and is particularly strong in the Northern Hemisphere subpolar gyres, the Arctic, and in a band north of the Antarctic Circumpolar Current (ACC; Fig. 4b); these are locations where heat is 


\section{Scenario 2040}

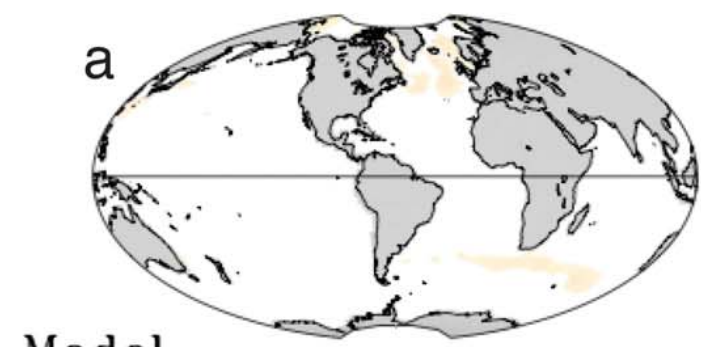

\section{Model}

\section{Internal}
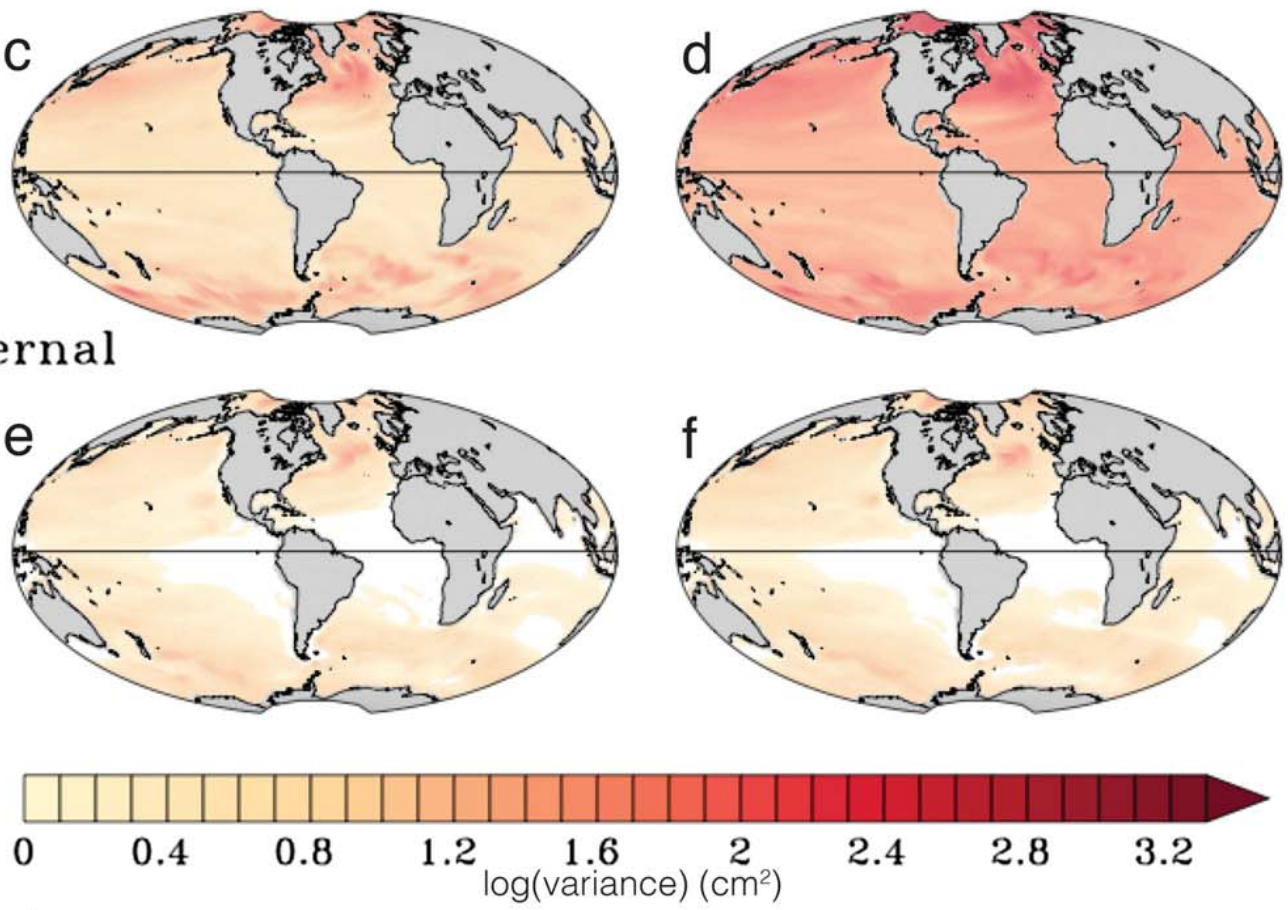

\section{Model/Total}
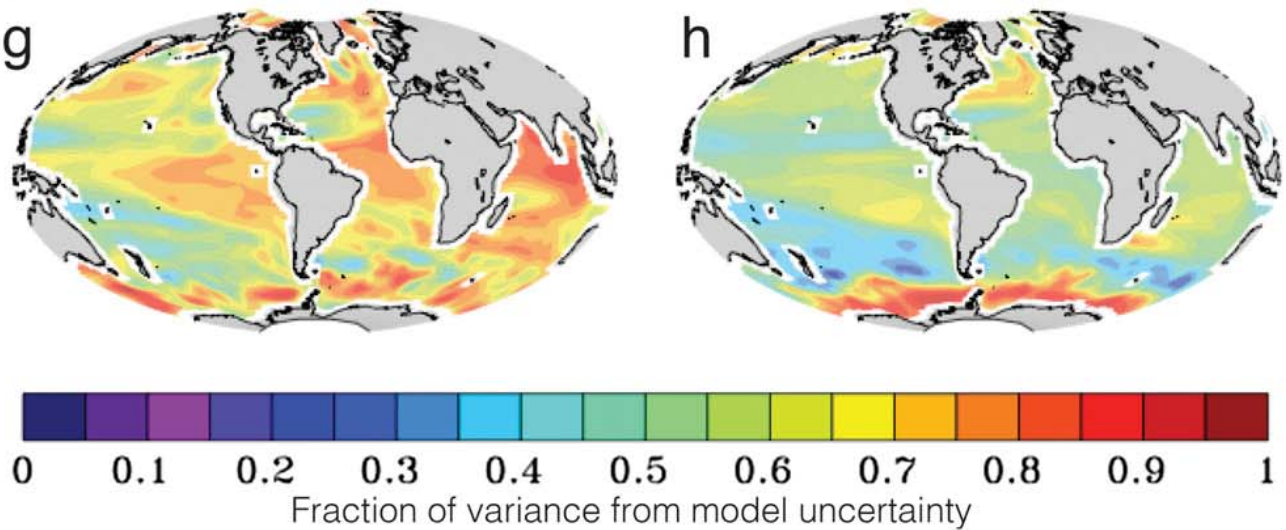

FIG. 4. The (left) 2040 and (right) 2090 variance in SLR ( $\mathrm{cm}^{2}$, on a log scale) for each of the main effects: (a),(b) scenario uncertainty $S(t)$; (c),(d) model uncertainty $M(t)$; and (e),(f) internal variability $V(t)$. (g),(h) The fraction of the variance in SLR $\left(\mathrm{cm}^{2}\right)$ contributed by model uncertainty $[M(t) / T(t)]$.

entering the ocean (Kuhlbrodt and Gregory 2012; Bouttes and Gregory 2014). There is virtually no scenario uncertainty south of the ACC, indicating that changes in the Southern Ocean are largely due to a scenario-independent dynamic response, often attributed to strengthening westerlies (Bouttes and Gregory 2014).

In both time periods and in almost all global locations, model uncertainty (Figs. 4c,d) is larger than scenario 


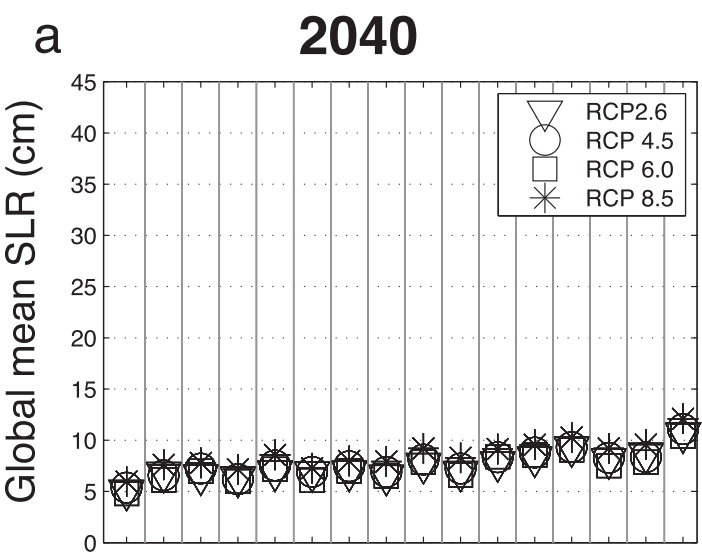

b

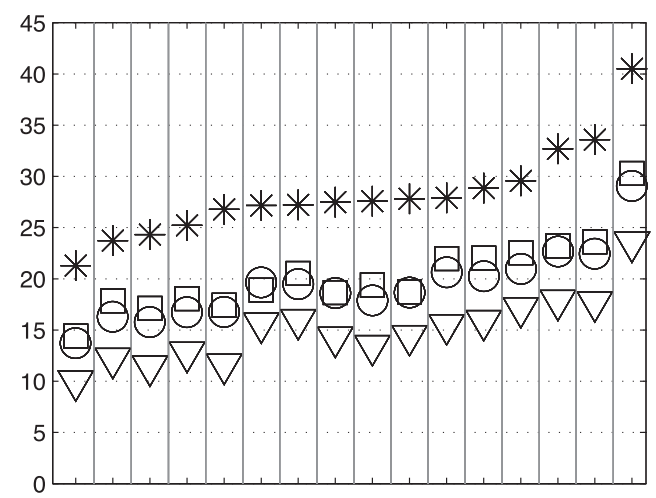

C

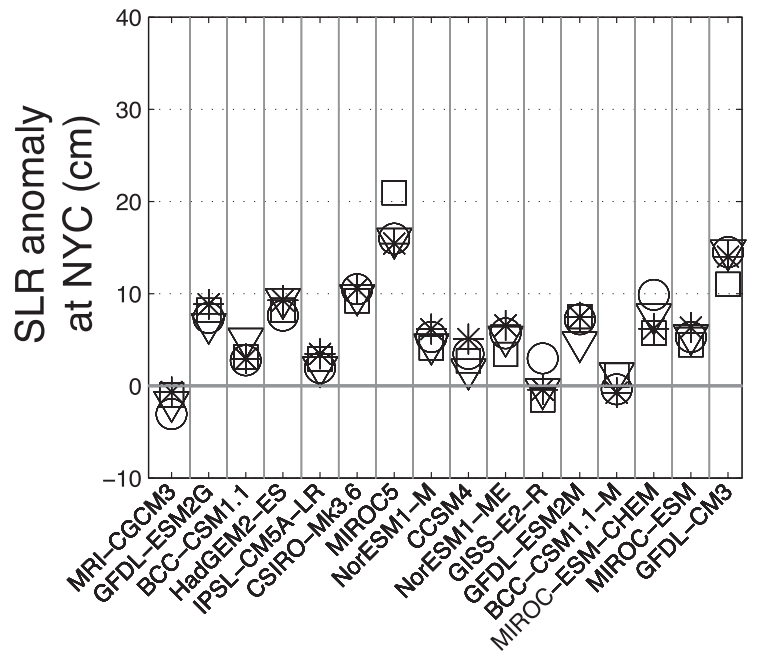

d

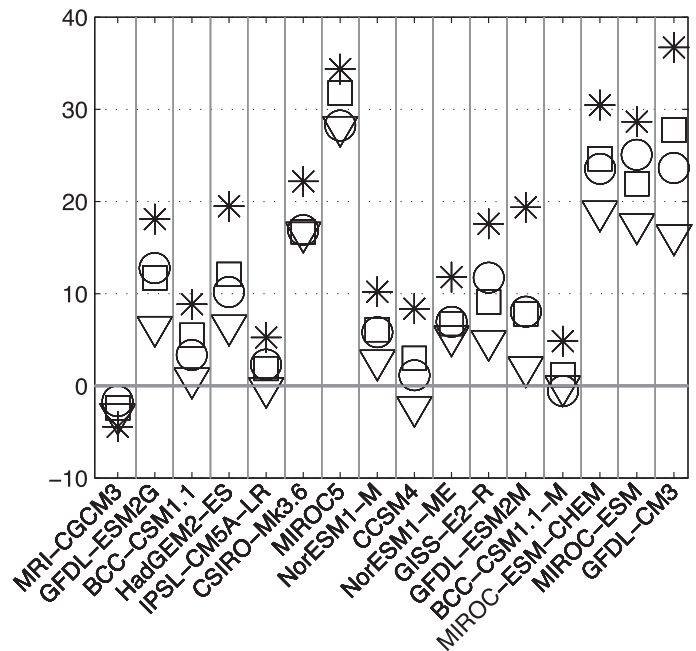

FIG. 5. The (left) 2040 and (right) 2090 model-scenario mean SLR, for (a),(b) the global mean and (c),(d) the local anomaly at NYC. Each symbol represents an RCP scenario (RCP2.6, triangles; RCP4.5, circles; RCP6.0, squares; RCP8.5, asterisks). Models are listed in ascending order of 2090 global mean sea level change for RCP8.5.

uncertainty, with maxima in the North Atlantic subpolar gyre and the Arctic and minima in the Southern Hemisphere midlatitudes, especially in the Pacific (Fig. 4c). The global dominance of model uncertainty late in the twenty-first century is highlighted in Figs. $4 \mathrm{~g}$ and $4 \mathrm{~h}$. Although it is highest as a fraction of the total variance in the Southern Ocean, model uncertainty is also high in the North Atlantic hotspot, where up to $75 \%$ of the variance is due to model spread.

In contrast to the other components, internal variability (Figs. 4e,f) does not grow in time, which means that internal variability, as described by this multimodel metric, does not change under a warming climate. Spatially, variability is maximized in the western Pacific, Arctic, and the North Atlantic subpolar gyre, locations in which various modes of decadal and multidecadal variability (including the Pacific decadal and North Atlantic oscillations) are particularly strong (Liu 2012).

\section{c. Model comparison}

We examine individual AOGCM projections in this section: first, by comparing model-scenario mean projections $[\operatorname{SLR}(m, \cdot, s, t)]$ for each of the 16 models, and second, by comparing four realizations of three models for all RCPs.

\section{1) Model-SCenario MeAn PRojections}

Projections of individual models averaged across realizations (Fig. 5) underscore the lack of differentiation between scenarios in the first half of the twenty-first century. By the late twenty-first century, GMSL rise is monotonic with end-of-century forcing. However, there is virtually no difference between RCP4.5 and RCP6.0, as the different evolution of forcing in these two scenarios is integrated by the sea level response. Most of the intramodel spread is driven by RCP8.5. The interscenario difference in GMSL is consistent across models, indicating 
that the sensitivity of GMSL to incremental forcing beyond that specified in RCP2.6 is very similar over the twenty-first century (revealing why model-scenario uncertainty is relatively small in Fig. 3).

Figures $5 \mathrm{c}$ and $5 \mathrm{~d}$ compare the sea level anomaly at NYC to more clearly distinguish each AOGCM's local response. By 2040 at NYC, models exhibit nonmonotonic changes with RCPs that are amplified later in the century. As noted by earlier studies (Yin et al. 2009; Yin 2012; Horton et al. 2010), there is a common, scenariodependent increase in the NYC anomaly by the end of the century; however, it remains relatively small $(<12 \mathrm{~cm}$ across all RCP scenarios) in seven models. GFDL CM3 and the two MIROC-ESMs project the highest GMSL and NYSL anomaly in this ensemble. MRI-CGCM3 is a low outlier in both GMSL and the local NYC anomaly, with a total NYSL rise of less than $20 \mathrm{~cm}$ by 2090 for all scenarios. These four models also bound the GMSL projections in the ensemble used by Yin (2012). In these four models, there is a correlation between SLR anomalies at NYC and the global mean for each model that strengthens with stronger forcing (Fig. 6). CSIRO Mk3.6.0 and MIROC5 also project high SLR anomalies at NYC, with more moderate rates of GMSL rise.

\section{2) INDIVIDUAL REALIZATIONS}

To compare internal variability across AOGCMs, we present time series of SLR from three models-CCSM4 (left), CSIRO Mk3.6.0 (center), and HadGEM2-ES (right)-in Fig. 7. Although not a comprehensive set, these are the only models that include four or more realizations for each of the four RCPs, and they are indicative of the range of scenario dependence and internal variability in this ensemble. Additionally, this analysis of four CCSM4 realizations may be compared to the larger ensemble of Hu and Deser (2013).

In the global mean (Figs.7a-c), realizations vary by less than $1 \mathrm{~cm}$, and scenarios are clearly seen to differentiate (emerge) in the 2040s. Because decadal-timescale internal variability in GMSL is small, the time of emergence is driven by the magnitude and response time of the forced change.

The NYC results (Figs. 7d-f) indicate that differences between scenarios at a local level can be obscured by internal variability well into the second half of the century, particularly for RCP2.6, RCP4.5, and RCP6.0. By quantifying the magnitude of the uncertainty due to scenario and internal variability for each of these models (Figs. 7g-i), it is evident that 1) scenario and internal variability in any individual model are not stable over time and 2) there are large intermodel differences in the magnitude of internal variability, even if the same number of realizations (four) are included for each

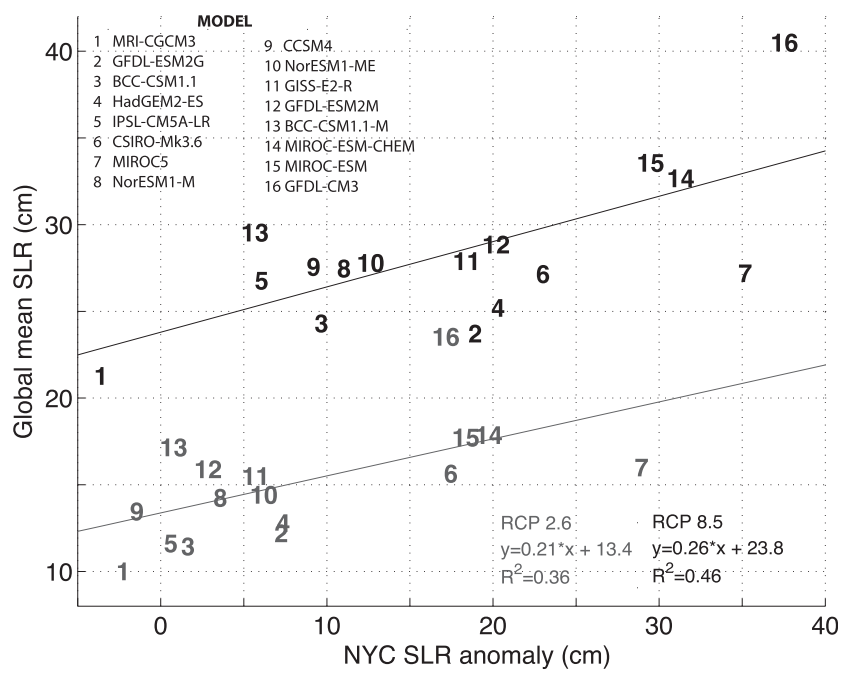

FIG. 6. Comparison of the 2090 ensemble mean change in GMSL and NYC anomaly for each AOGCM, for RCP2.6 (gray) and RCP8.5 (black). Numbers correspond to models listed in ascending order of 2090 GMSL change for RCP8.5.

AOGCM. These differences result in crossover times at NYC of 2030, 2045, and 2055 for the three models. The earlier emergence of scenario dependence in CCSM4 is driven by smaller internal variability (the CSIRO Mk3.6.0 and HadGEM2-ES mean twenty-first-century variability of $\sim 30 \mathrm{~cm}^{2}$ is almost an order of magnitude larger than the CCSM4), while the late emergence of HadGEM2-ES is also influenced by a weaker sea level response.

We examine the magnitude of scenario uncertainty and internal variability around the crossover time (2050) in Fig. 8. In general, the spatial patterns of scenario dependence and internal variability are similar across the three AOGCMs, but the magnitude varies, particularly with respect to internal variability. The ranking of the models' internal variability appears to be similar in all global locations, with HadGEM2-ES showing the greatest variability.

The crossover time metric allows local differences in scenario dependence to be quantified for both the ensemble (Fig. 9a) and individual models (Figs. 9b-d). The local crossover time derived from the model ensemble can vary from the 2040s to beyond the twenty-first century, with later emergence driven by low scenario uncertainty and/or high internal variability (Fig. 8). In general, crossover occurs earlier in the tropics; however, scenarios emerge far earlier in the Atlantic and Indian Oceans than in the Pacific (up to 25 years earlier at the same latitude). This is driven by the generally weak decadal-time-scale tropical internal variability and the more robust scenario-dependent sea level changes in the Pacific. Although there is a strong scenario-dependent 

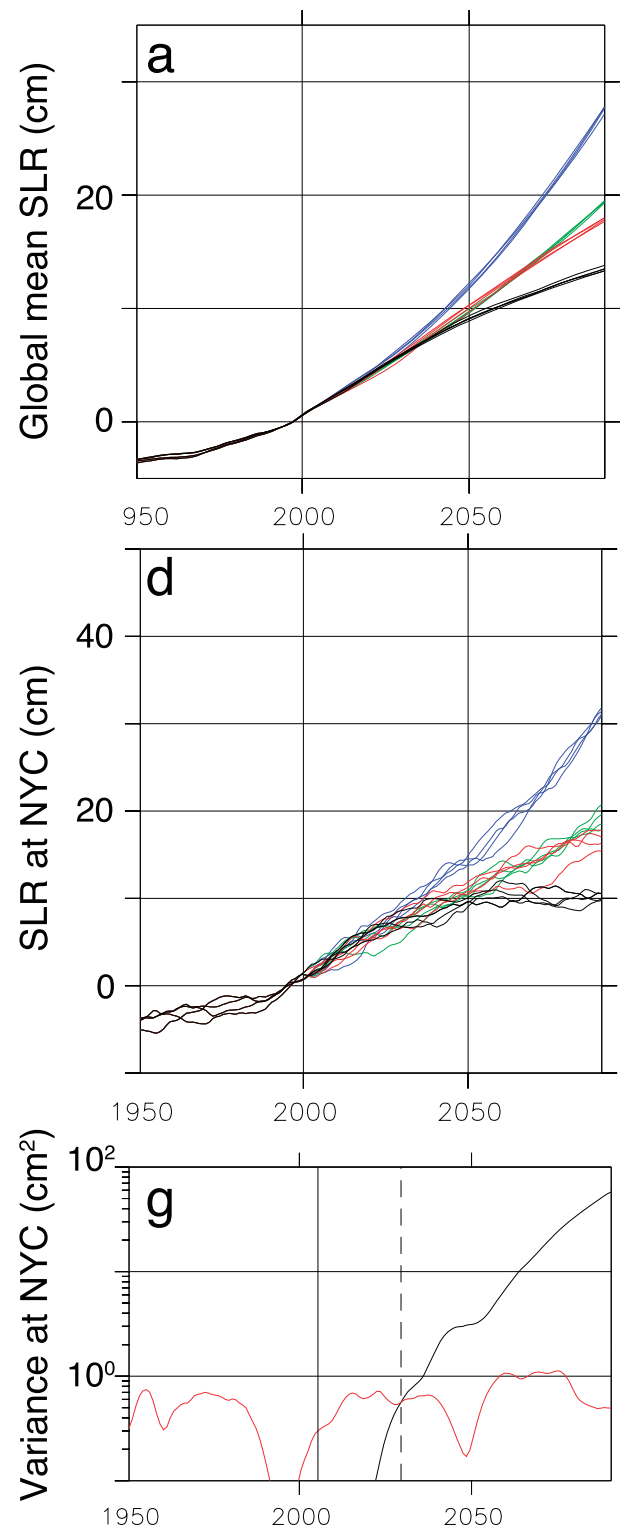

FIG. 7. Time series of (a)-(c) GMSL and (d)-(f) NYSL rise (in $\mathrm{cm}$ ) from four realizations of the (left) CCSM4, (middle) CSIRO Mk3.6.0, and (right) HadGEM2-ES models. Colors indicate RCP (blue, 8.5; green, 6.0; red, 4.5; black, 2.6). (g)-(i) The NYSL variance (in $\mathrm{cm}^{2}$ ) contributed by internal variability (red) and scenario uncertainty (black). Dashed vertical line indicates the crossover time.

signal in the North Atlantic, it is collocated with a region of high model spread. The only locations where different emission trajectories are apparent before 2050 are the tropical Atlantic and Indian Oceans.

The spatial pattern of emergence is somewhat consistent between the ensemble and the individual models, but the individual models show 1) a much earlier emergence and 2) a few notable differences in spatial patterns. CCSM4, with its relatively low internal variability, drives an earlier, and fairly uniform, emergence; the other two models have regions of high internal variability (Fig. 8) in the northern subtropical and subpolar gyres that obscure the response to different RCPs.

\section{Discussion}

Our results indicate that uncertainty in the oceanographic component of sea level change is dominated by AOGCM spread over much of the globe through 2100 and that the magnitude of internal variability varies widely across AOGCMs. This discussion focuses on the implications of these findings on projections of sea level and the emergence of a scenario-dependent sea level trend. We do not attempt to evaluate individual models; rather, we suggest possible origins of model divergence, highlight outliers, and underscore their importance to local risk assessments. 


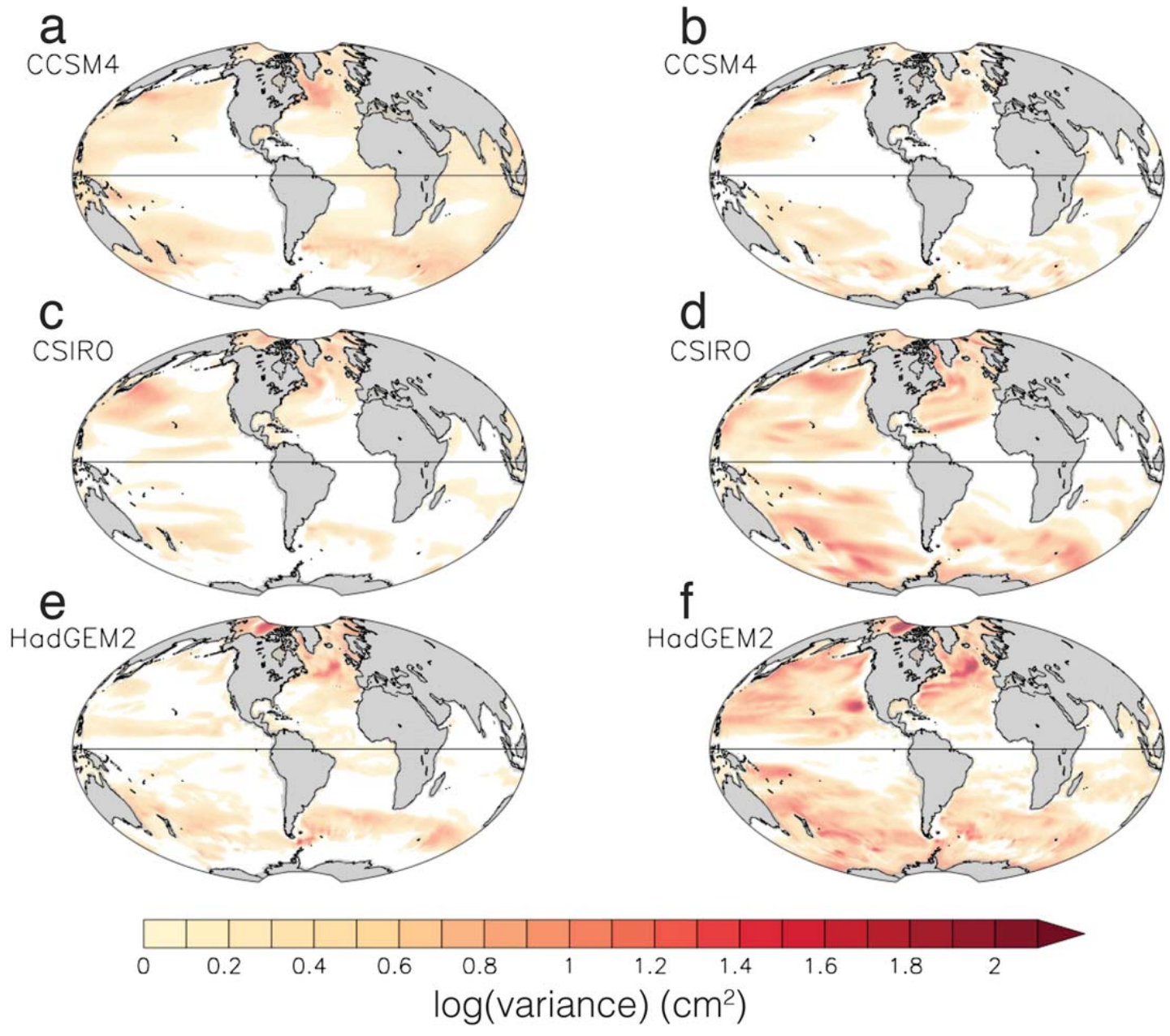

FIG. 8. The variance in SLR due to (left) scenario uncertainty and (right) internal variability in 2050 for four realizations of the (a),(b) CCSM4; (c),(d) CSIRO Mk.3.6.0; and (e),(f) HadGEM2-ES models. Note log scale (in $\mathrm{cm}^{2}$ ).

\section{a. Origins of model spread}

Several properties of ocean models have been invoked to explain the spread in CMIP5 GMSL projections. Kuhlbrodt and Gregory (2012) emphasize the importance of the vertical temperature structure and its role in governing twenty-first-century stratification. In the North Atlantic and the Southern Ocean, where eddies and convection are responsible for much of the vertical heat transport, parameterizations of these small-scale processes across CMIP5 models may lead to differing magnitudes of twenty-first-century heat uptake (Church et al. 2014). Using two GFDL-ESMs, Hallberg et al. (2013) show that temperature biases (via their influence on thermal expansion coefficients) and differences in vertical mixing drive roughly equivalent differences in twenty-first-century GMSL rise. These factors-temperature biases, upper-ocean stratification, and vertical mixing - are difficult to separate, but their combined effect is likely to be involved in the varying representation of thermosteric sea change across AOGCMs.

Differences in atmospheric models are also relevant to GMSL. For example, the ocean component of GFDL CM3 is very similar to GFDL-ESM2M, which has a 2090 GMSL rise of $29 \mathrm{~cm}$. The substantially higher GMSL in CM3 $(40 \mathrm{~cm})$ indicates that greater near-surface warming of the global ocean-driven by a stronger atmospheric feedbacks-is as, if not more, important than the different ocean model formulations represented in this ensemble.

NYSL is strongly influenced by the dynamics of the Atlantic meridional overturning circulation (AMOC). More specifically, a weakened AMOC has been shown to drive increases in NYSL in observations and models (Yin et al. 2009; Yin and Goddard 2013). The spread in the local anomaly at NYC in these CMIP5 models is likely to be driven primarily by the widely varying representation of this circulation. The two AOGCMs that bound the range of sea level changes in this analysis, 

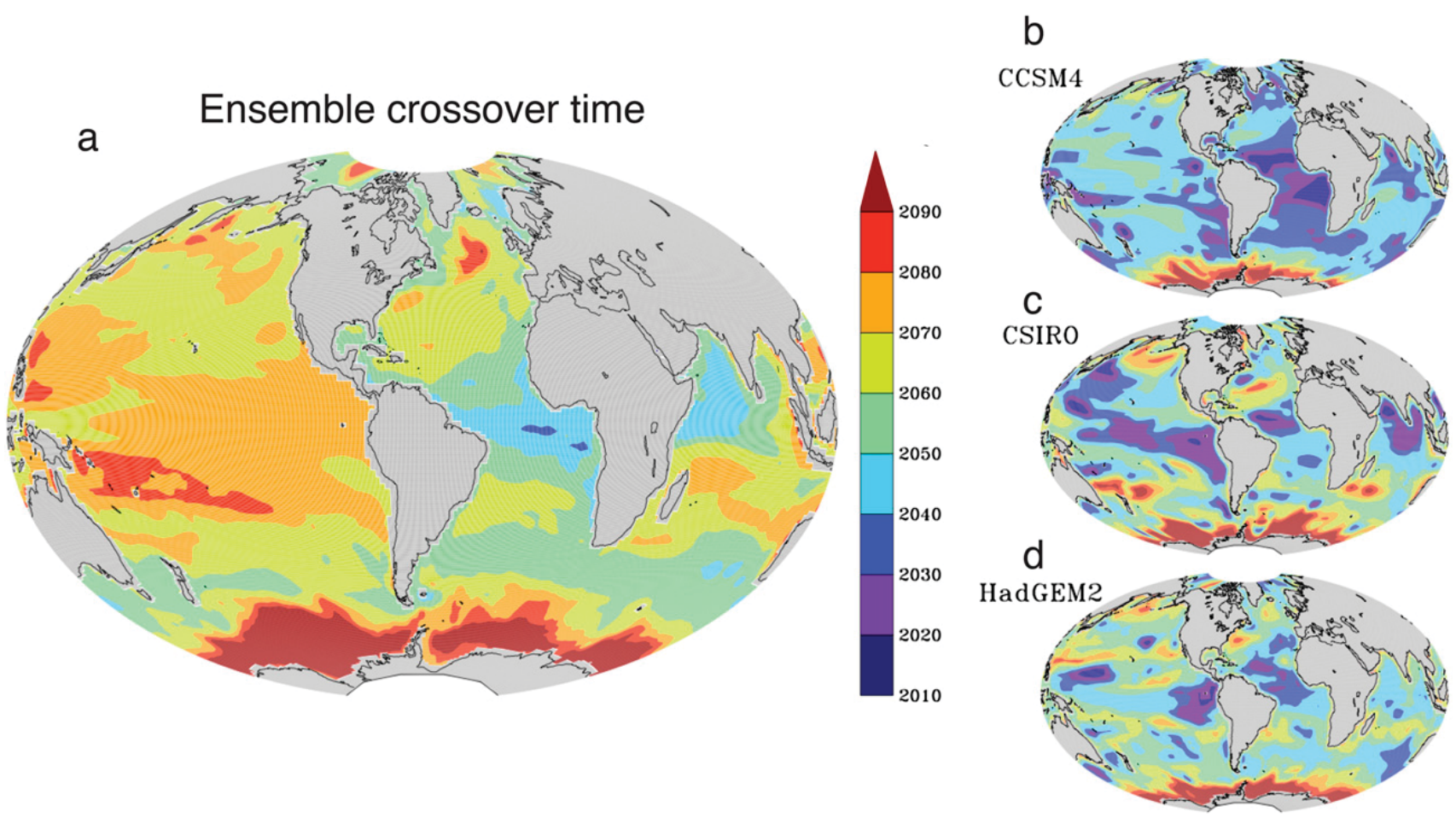

FIG. 9. The local crossover time; the year at which scenario uncertainty $[S(t)]$ first reaches a value larger than the variance due to internal variability $[V(t)]$ for (a) the multimodel ensemble and (b)-(d) the three individual models shown in Figs. 7 and 8.

GFDL CM3 and MRI-CGCM3, also bound the twentyfirst-century AMOC response in the set of models investigated by Cheng et al. (2013). By 2100 in the RCP8.5 simulation, AMOC declines by $\sim 60 \%$ from its mean historical strength in GFDL CM3 and $15 \%$ in the MRI model. Other AOGCMs cluster around declines of 30\%-40\% (Cheng et al. 2013; Weaver et al. 2012). At the local scale, the different resolution and bathymetry of each AOGCM are likely to contribute to model spread (Holt et al. 2009), although it is difficult to isolate any systematic effects.

In Fig. 6, outliers, particularly GFDL CM3 and the MIROC-ESM's, exhibit high GMSL rise and a high NYC anomaly. Although the mechanisms underlying this correlation require further study, we hypothesize that it is robust but indirect: models with stronger atmospheric feedbacks drive a simultaneous decline in the AMOC and enhanced warming of the upper ocean. Regardless of its origin, this correlation should be included in sea level assessments; considering GMSL and the local anomaly (e.g., the zostoga and zos fields in CMIP5 output) independently will artificially decrease uncertainty in late-century projections. In NYC and the northeastern U.S. coastline, this correlation widens the spread of projections considerably (Kopp et al. 2014).

In the Arctic, different AOGCM representations of ice-ocean processes result in a wide range of twenty-first-century declines in sea ice (Liu et al. 2013). Sea ice decline will influence ocean heat uptake, salinity, and/or circulation, although the precise mechanisms connecting sea ice and local sea level changes are complex and deserve further study.

\section{$b$. The influence of model spread on sea level projections}

In many coastal locations (including New York City), uncertainty in the oceanographic component of LSL comprises a large fraction of the total LSL uncertainty (Kopp et al. 2014; Perrette et al. 2013; Slangen et al. 2014). Thus, the treatment of the CMIP5 model spread, and, in particular, high and low outliers, meaningfully impacts LSL projections, especially if high-end (low probability) outcomes are targeted.

The effect of excluding outliers is shown in Fig. 10, in which the dark-shaded region indicates the range of the central 10 AOGCM projections (approximately the middle $66 \%$ of the ensemble). The exclusion of six models reduces the 2090 GMSL rise spread by $\sim 75 \%$ to $25-30 \mathrm{~cm}$. At NYC, the spread is reduced by $\sim 50 \%$ to $33-56 \mathrm{~cm}$. The range of projections may also be widened by its treatment in an assessment: if, as in the AR5, we make a (conservative) assumption that the 5th-95th range of model output constitutes the likely (67\%) range, the implied range of projections in this ensemble would be much larger. 
a

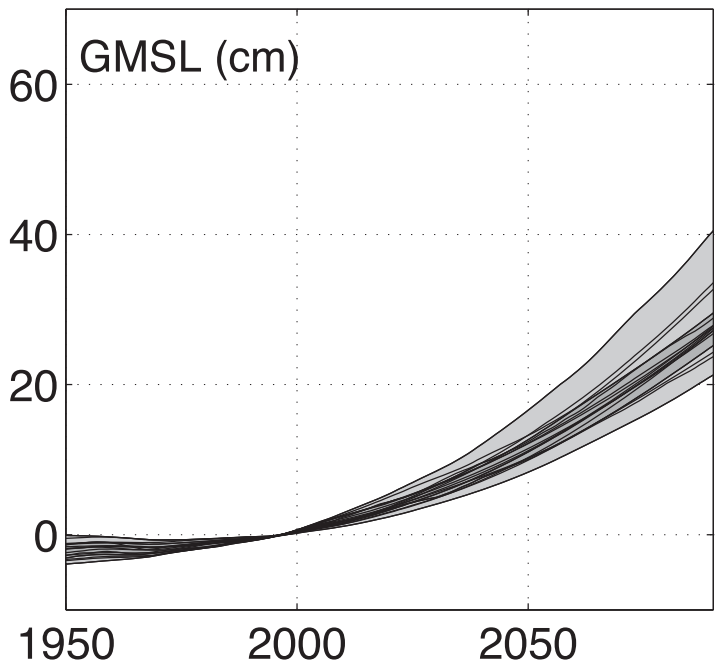

b

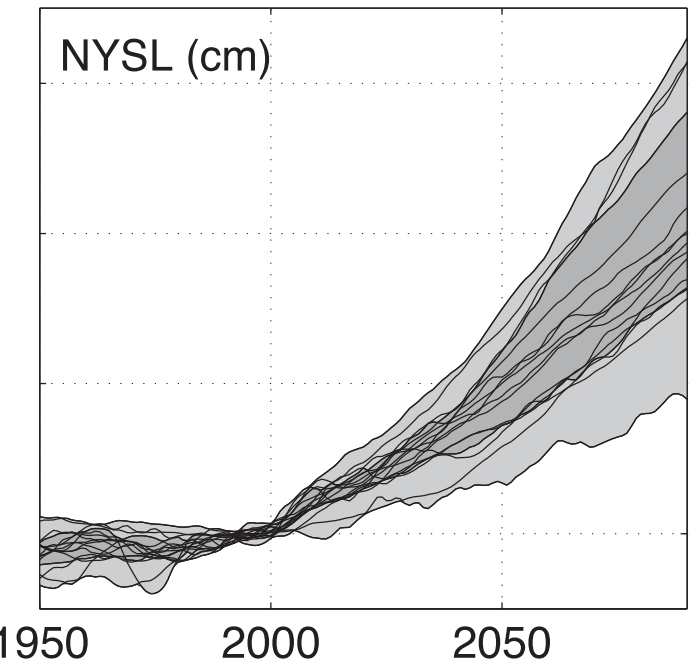

FIG. 10. Time series of model-scenario mean (a) GMSL and (b) NYSL rise for RCP 8.5 (in cm). Each line is a single AOGCM; light shading indicates the ensemble range; darker shading encompasses the central 10 models at each time.

Figure 10 is intended to be heuristic; however, it indicates that exclusion or weighting schemes based on topdown observational metrics-for example, temperature biases, heat uptake, and/or AMOC behavior-will have a substantial impact on projections. Although evaluating AOGCMs is difficult (Tebaldi and Knutti 2007; Santer et al. 2009; Sansom et al. 2013), these sea level metrics integrate over many processes and thus may be reliable indicators of model performance (Reichler and Kim 2008; Tebaldi and Knutti 2007). Furthermore, because of the long response times of the deep ocean (Church et al. 2014; Gregory et al. 2013), much of the twenty-first-century sea level response is driven by twentieth and early twenty-first-century forcing. The memory of GMSL, and its sensitivity to initial conditions (Hallberg et al. 2013), implies that models that better reflect sea level trends and hydrography in the observed period will give better projections over the twenty-first century. We also note the potential for implicit weighting if all models are considered equal. Here, our ensemble was selected using one criterion: the availability of all four RCPs. This ensemble included several models that originate from the same modeling center. Although some of these AOGCMs exhibit diversity in their response (i.e., GFDL and BCC), the two NorESMs and MIROC-ESMs provide very similar sea level projections, suggesting that it is unreasonable to consider these models independent.

We thus encourage efforts to evaluate and/or weight sea level projections by their performance against observations. However, we highlight three cautionary notes. First, there is a limited number of AOGCMs (some of which share ocean model components); downweighting will effectively shrink the sample size included in assessments. Second, the central range may be systematically biased, either because of limitations in historical forcing (Gupta et al. 2013; Gregory et al. 2013) or AOGCM representation of ocean heat uptake processes (Church et al. 2014). Third, significant efforts to reduce uncertainty in the oceanographic component of LSL should take place alongside other components of the LSL budget (e.g., freshwater additions from ice sheet and glacier mass changes and vertical land motion). In the future, the uncertainty analysis techniques employed here may be adapted to include these additional sources of sea level change, facilitating a clear prioritization of uncertainty reduction efforts.

\section{c. The importance of internal variability}

Although the attribution of an anthropogenic signal in global mean sea level is clear (Marcos and Amores 2014; Church et al. 2014), our results suggest that the influence of different radiative forcing trajectories on sea level is obscured (especially at the local level) in the twenty-first century by 1) long oceanic response times, 2) high model uncertainty in regions of large sea level change, and 3) varying model representations of internal variability. Furthermore, our results emphasize that the time of emergence will vary greatly depending on a model's climate forcing, response to climate forcing, and representation of internal variability.

To characterize internal variability, we have used a subset of models with a limited number of realizations, 
averaged over subdecadal time periods, and may not have captured lower frequency modes (Chambers et al. 2012). The magnitude of internal variability may increase with more realizations (Deser et al. 2012) or increased model complexity (Olson et al. 2013); we also cannot judge whether the CMIP5 AOGCMs with multiple realizations comprise a representative subset. Furthermore, with many models contributing only one realization, there is the potential for mischaracterizing internal variability as model uncertainty.

The importance of characterizing internal variability for early-to-midcentury sea level projections and detection suggests work should continue along two fronts: 1) developing alternate techniques to capture the representation of internal variability in models (Hawkins and Sutton 2009; Imbers et al. 2014; Haigh et al. 2014), perhaps using long-term control runs and/or synthetic techniques, and 2) model-data comparison aimed at determining whether model-based methods capture observed modes of sea level variability, particularly those relevant to long-term climate changes.

\section{Conclusions}

We have investigated the magnitude and sources of uncertainty in twenty-first-century CMIP5 projections of the oceanographic component in sea level at a global and local scale, using New York City as a case study. In the global mean, uncertainty in SLR due to different RCPs (here referred to as scenario dependence) is smaller than that resulting from different AOGCMs (model, or structural, uncertainty) throughout most of the twenty-first century and smaller than model-derived estimates of internal variability through approximately 2035. Scenario dependence is driven largely by RCP8.5; sea level exhibits a limited dependence on other RCPs over the twenty-first century.

Locally, the fractional contribution of each source of uncertainty to the total is highly spatially variable. All sources are largest in the North Atlantic and the Arctic Ocean, likely because of the widely varying AOGCM representations of the Atlantic meridional overturning circulation and sea ice processes.

The wide spread of model projections of sea level trends and variability, particularly in the North Atlantic, implies that 1) the choice (or weighting) of models is important for ensemble projections of oceanic quantities such as sea level and 2) the emergence of scenario dependence will vary depending on location and on the model used (later in a model with a higher degree of internal variability and/or weaker scenario dependence). Four models exhibit a significant deviation from the multimodel mean in both global mean SLR and SLR at
New York City. The inclusion of these outliers dramatically changes projections; if the central 10 models are used ( $\sim 67 \%$ range), the 2090 global mean sea level spread decreases by $75 \%$. We suggest that the dynamics and/or realism of these outlying models should be further investigated using top-down observational constraints (e.g., sea level change, ocean heat uptake, and temperature) and "twin" models to quantify formulation-related uncertainty. These efforts have the potential to drive meaningful uncertainty reductions.

Fairly uniformly over the globe, internal variability is as large as that due to RCPs until 2050; in some locations, this "crossover" does not occur in the twenty-first century. Local sea level assessments should thus consider the role of regional internal variability and should not expect a differentiation of SLR trajectories for different emissions scenarios through at least midcentury. In the northeastern United States, this differentiation could be obscured through most of the twenty-first century, even if the spread between ocean climate models is substantially reduced.

Acknowledgments. The authors thank the New York City Panel on Climate Change for inspiring this analysis. The NOAA Geophysical Fluid Dynamics Laboratory provided data and analysis tools. We thank Jianjun Yin for providing data for comparison and for early discussions and Robert Hallberg and Ron Stouffer for their insight into CMIP5 sea level projections. C.M.L. is grateful for financial support from the Science, Technology and Environmental Policy program in the Woodrow Wilson School of Public and International Affairs at Princeton University, the Carbon Mitigation Initiative in the Princeton Environmental Institute, and the Structures of Coastal Resilience project. R.E.K.'s contribution to this project was supported by the Risky Business Initiative. R.M.H.'s contribution was supported by NOAA's Regional Integrated Sciences and Assessments (RISA) program. We acknowledge the World Climate Research Programme's Working Group on Coupled Modeling, which is responsible for CMIP, and we thank the climate modeling groups (listed in Table 1) for producing and making available their model output. For CMIP, the U.S. Department of Energy's Program for Climate Model Diagnosis and Intercomparison provides coordinating support and led development of software infrastructure in partnership with the Global Organization for Earth System Science Portals.

\section{REFERENCES}

Bouttes, N., and J. M. Gregory, 2014: Attribution of the spatial pattern of $\mathrm{CO}_{2}$-forced sea level change to ocean surface 
flux changes. Environ. Res. Lett., 9, 034004, doi:10.1088/ 1748-9326/9/3/034004.

Chambers, D. P., M. A. Merrifield, and R. S. Nerem, 2012: Is there a 60-year oscillation in global mean sea level? Geophys. Res. Lett., 39, L18607, doi:10.1029/2012GL052885.

Cheng, W., J. C. H. Chiang, and D. Zhang, 2013: Atlantic meridional overturning circulation (AMOC) in CMIP5 models: RCP and historical simulations. J. Climate, 26, 7187-7197, doi:10.1175/JCLI-D-12-00496.1.

Church, J., J. Gregory, N. White, S. Platten, and J. Mitrovica, 2011: Understanding and projecting sea level change. Oceanography, 24, 130-143, doi:10.5670/oceanog.2011.33.

Church, J. A., and Coauthors, 2014: Sea level change. Climate Change 2013: The Physical Science Basis, T. F. Stocker et al., Eds., Cambridge University Press, 1029-1136.

Deser, C., A. Phillips, V. Bourdette, and H. Teng, 2012: Uncertainty in climate change projections: the role of internal variability. Climate Dyn., 38, 527-546, doi:10.1007/s00382-010-0977-x.

Gregory, J., and Coauthors, 2013: Climate models without preindustrial volcanic forcing underestimate historical ocean thermal expansion. Geophys. Res. Lett., 40, 1600-1604, doi:10.1002/ grl.50339.

Gupta, A. S., N. C. Jourdain, J. N. Brown, and D. Monselesan, 2013: Climate drift in the CMIP5 models. J. Climate, 26, 8597 8615, doi:10.1175/JCLI-D-12-00521.1.

Haigh, I. D., T. Wahl, E. J. Rohling, R. Price, C. B. Pattiaratchi, F. M. Calafat, and S. Dangendorf, 2014: Timescales for detecting a significant acceleration in sea level rise. Nat. Commun., 5, 3635, doi:10.1038/ncomms4635.

Hallberg, R., A. Adcroft, J. P. Dunne, J. P. Krasting, and R. J. Stouffer, 2013: Sensitivity of twenty-first-century global-mean steric sea level rise to ocean model formulation. J. Climate, 26, 2947-2956, doi:10.1175/JCLI-D-12-00506.1.

Hallegatte, S., C. Green, R. J. Nicholls, and J. Corfee-Morlot, 2013 Future flood losses in major coastal cities. Nat. Climate Change, 3, 802-806, doi:10.1038/nclimate1979.

Hawkins, E., and R. Sutton, 2009: The potential to narrow uncertainty in regional climate predictions. Bull. Amer. Meteor. Soc., 90, 1095-1107, doi:10.1175/2009BAMS2607.1.

$\longrightarrow$, and - 2012: Time of emergence of climate signals. Geophys. Res. Lett., 39, L01702, doi:10.1029/2011GL050087.

Hinkel, J., and Coauthors, 2014: Coastal flood damage and adaptation costs under 21st century sea-level rise. Proc. Natl. Acad. Sci. USA, 111, 3292-3297, doi:10.1073/pnas.1222469111.

Holt, J., and Coauthors, 2009: Modelling the global coastal ocean. Philos. Trans. Roy. Soc. London, A367, 939-951, doi:10.1098/ rsta.2008.0210.

Horton, R., V. Gornitz, M. Bowman, and R. Blake, 2010: Climate observations and projections. Ann. N. Y. Acad. Sci., 1196, 4162, doi:10.1111/j.1749-6632.2009.05314.x.

$\mathrm{Hu}$, A., and C. Deser, 2013: Uncertainty in future regional sea level rise due to internal climate variability. Geophys. Res. Lett., 40, 2768-2772, doi:10.1002/grl.50531.

Imbers, J., A. Lopez, C. Huntingford, and M. Allen, 2014: Sensitivity of climate change detection and attribution to the characterization of internal climate variability. J. Climate, 27, 3477-3491, doi:10.1175/JCLI-D-12-00622.1.

Knutti, R., R. Furrer, C. Tebaldi, J. Cermak, and G. A. Meehl, 2010: Challenges in combining projections from multiple climate models. J. Climate, 23, 2739-2758, doi:10.1175/ 2009JCLI3361.1.

Kopp, R. E., R. M. Horton, C. M. Little, J. X. Mitrovica, M. Oppenheimer, D. J. Rasmussen, B. H. Strauss, and
C. Tebaldi, 2014: Probabilistic 21st and 22nd century sealevel projections at a global network of tide gauge sites. Earth's Future, 2, 383-406, doi:10.1002/2014EF000239.

Kuhlbrodt, T., and J. M. Gregory, 2012: Ocean heat uptake and its consequences for the magnitude of sea level rise and climate change. Geophys. Res. Lett., 39, L18608, doi:10.1029/ 2012GL052952.

Liu, J., M. Song, R. M. Horton, and Y. Hu, 2013: Reducing spread in climate model projections of a September ice-free Arctic. Proc. Natl. Acad. Sci., 110, 12571-12576, doi:10.1073/ pnas.1219716110.

Liu, Z., 2012: Dynamics of interdecadal climate variability: A historical perspective. J. Climate, 25, 1963-1995, doi:10.1175/ 2011JCLI3980.1.

Marcos, M., and A. Amores, 2014: Quantifying anthropogenic and natural contributions to thermosteric sea level rise. Geophys. Res. Lett., 41, 2502-2507, doi:10.1002/2014GL059766.

Milne, G. A., W. R. Gehrels, C. W. Hughes, and M. E. Tamisiea, 2009: Identifying the causes of sea-level change. Nat. Geosci., 2, 471-478, doi:10.1038/ngeo544.

National Research Council, 2012: Sea-Level Rise for the Coasts of California, Oregon, and Washington: Past, Present, and Future. National Academies Press, 201 pp.

NPCC2, 2013: Climate risk information 2013: Observations, climate change projections, and maps. New York City Panel on Climate Change Rep., 35 pp. [Available online at www. nyc.gov/html/planyc2030/downloads/pdf/npcc_climate_risk_ information_2013_report.pdf.]

Olson, R., R. Sriver, W. Chang, M. Haran, N. M. Urban, and $\mathrm{K}$. Keller, 2013: What is the effect of unresolved internal climate variability on climate sensitivity estimates? J. Geophys. Res. Atmos., 118, 4348-4358, doi:10.1002/jgrd.50390.

Pardaens, A. K., J. M. Gregory, and J. A. Lowe, 2011: A model study of factors influencing projected changes in regional sea level over the twenty-first century. Climate Dyn., 36, 20152033, doi:10.1007/s00382-009-0738-x.

Perrette, M., F. Landerer, R. Riva, K. Frieler, and M. Meinshausen, 2013: A scaling approach to project regional sea level rise and its uncertainties. Earth Syst. Dyn., 4, 11-29, doi:10.5194/ esd-4-11-2013.

Reichler, T., and J. Kim, 2008: How well do coupled models simulate today's climate? Bull. Amer. Meteor. Soc., 89, 303-311, doi:10.1175/BAMS-89-3-303.

Sansom, P. G., D. B. Stephenson, C. A. T. Ferro, G. Zappa, and L. Shaffrey, 2013: Simple uncertainty frameworks for selecting weighting schemes and interpreting multimodel ensemble climate change experiments. J. Climate, 26, 4017-4037, doi:10.1175/ JCLI-D-12-00462.1.

Santer, B. D., and Coauthors, 2009: Incorporating model quality information in climate change detection and attribution studies. Proc. Natl. Acad. Sci., 106, 14778-14783, doi:10.1073/ pnas.0901736106.

Slangen, A. B. A., M. Carson, C. A. Katsman, R. S. W. van de Wal, A. Köhl, L. L. A. Vermeersen, and D. Stammer, 2014: Projecting twenty-first century regional sea-level changes. Climatic Change, 124, 317-332, doi:10.1007/ s10584-014-1080-9.

Stammer, D., A. Cazenave, R. M. Ponte, and M. E. Tamisiea, 2013: Causes for contemporary regional sea level changes. Annu. Rev. Mar. Sci., 5, 21-46, doi:10.1146/annurev-marine-121211-172406.

Taylor, K. E., R. J. Stouffer, and G. A. Meehl, 2012: An overview of CMIP5 and the experiment design. Bull. Amer. Meteor. Soc., 93, 485-498, doi:10.1175/BAMS-D-11-00094.1. 
Tebaldi, C., and R. Knutti, 2007: The use of the multi-model ensemble in probabilistic climate projections. Philos. Trans. Roy. Soc. London, A365, 2053-2075, doi:10.1098/rsta.2007.2076.

Weaver, A. J., and Coauthors, 2012: Stability of the Atlantic meridional overturning circulation: A model intercomparison. Geophys. Res. Lett., 39, L20709, doi:10.1029/2012GL053763.

Yin, J., 2012: Century to multi-century sea level rise projections from CMIP5 models. Geophys. Res. Lett., 39, L17709, doi:10.1029/2012GL052947.
- , and P. B. Goddard, 2013: Oceanic control of sea level rise patterns along the East Coast of the United States. Geophys. Res. Lett., 40, 5514-5520, doi:10.1002/2013GL057992.

—, M. E. Schlesinger, and R. J. Stouffer, 2009: Model projections of rapid sea-level rise on the northeast coast of the United States. Nat. Geosci., 2, 262-266, doi:10.1038/ngeo462.

Yip, S., C. A. T. Ferro, D. B. Stephenson, and E. Hawkins, 2011: A simple, coherent framework for partitioning uncertainty in climate predictions. J. Climate, 24, 4634-4643, doi:10.1175/2011JCLI4085.1. 